\title{
Heavy-metal detectors based on modified ferrite nanoparticles
}

\author{
Urszula Klekotka ${ }^{1}$, Ewelina Wińska ${ }^{1}$, Elżbieta Zambrzycka-Szelewa ${ }^{1}$, Dariusz Satuła ${ }^{2}$ \\ and Beata Kalska-Szostko*1
}

\author{
Full Research Paper \\ Address: \\ ${ }^{1}$ Institute of Chemistry, University of Białystok, Ciołkowskiego $1 \mathrm{~K}$, \\ 15-245, Białystok Poland and ${ }^{2}$ Faculty of Physics, University of \\ Białystok, Ciołkowskiego 1L, 15-245, Białystok, Poland \\ Email: \\ Beata Kalska-Szostko* - kalska@uwb.edu.pl \\ * Corresponding author \\ Keywords: \\ ferrite nanoparticles; heavy metal detection; materials \\ characterization; water purification
}

Open Access

\author{
Beilstein J. Nanotechnol. 2018, 9, 762-770. \\ doi:10.3762/bjnano.9.69 \\ Received: 13 October 2017 \\ Accepted: 30 January 2018 \\ Published: 28 February 2018 \\ This article is part of the Thematic Series "Energy conversion, storage \\ and environmental remediation using nanomaterials". \\ Guest Editor: W.-J. Ong \\ (C) 2018 Klekotka et al.; licensee Beilstein-Institut. \\ License and terms: see end of document.
}

\begin{abstract}
In this work, we analyze artificial heavy-metal solutions with ferrite nanoparticles. Measurements of adsorption effectiveness of different kinds of particles, pure magnetite or magnetite doped with calcium, cobalt, manganese, or nickel ions, were carried out. A dependence of the adsorption efficiency on the composition of the inorganic core has been observed. Ferrites surfaces were modified by phthalic anhydride (PA), succinic anhydride (SA), acetic anhydride (AA), 3-phosphonopropionic acid (3-PPA), or 16-phosphohexadecanoic acid (16-PHDA) to compare the adsorption capability of the heavy metals $\mathrm{Cd}, \mathrm{Cu}$ and $\mathrm{Pb}$. The obtained nanoparticles were structurally characterized by transmission electron microscopy (TEM), X-ray diffraction (XRD), Fourier transform infrared spectroscopy (FTIR) and Mössbauer spectroscopy. The amounts of $\mathrm{Cd}, \mathrm{Cu}$ and $\mathrm{Pb}$ were measured out by atomic absorption spectroscopy (AAS) and energy dispersive X-ray (EDX) as comparative techniques. The performed study shows that SA linker appears to be the most effective in the adsorption of heavy metals. Moreover, regarding the influence of the composition of the inorganic core on the detection ability, the most effective ferrite $\mathrm{Mn}_{0.5} \mathrm{Fe}_{2.5} \mathrm{O}_{4}$ was selected for discussion. The highest heavy-metal adsorption capability and universality was observed for SA as a surface modifier.
\end{abstract}

\section{Introduction}

Many research reports show that magnetic nanoparticles can be widely used in medicine for drug delivery, implants manufacture, as components of contrast agents in magnetic resonance imaging (MRI) as well as active centers in hyperthermia treatment [1]. The use of magnetic nanoparticles in drug delivery allows for a significant reduction of the amount of applied medications [2]. Also, one can imagine sensors based on nanostructures possessing very high sensitivity towards particular species due to the high surface area and specific reactivity $[3,4]$. However, very often not only surface termination but also core composition is of crucial importance for the required functionality.

In food industry or water purification, nanotechnology has begun to play a non-negligible role. However, to date it is considered to be a relatively new application area. Currently, 
nanostructures are mostly used to improve the quality of food, prolong its storage life, detect contaminants [5] and receive intelligent packaging [6]. A lot of research is focused on the reduction of the amount of fat in the products through the use of nanotechnological solutions. The idea to use fat in the forms of nanoemulsions, e.g., in cream or mayonnaise, became very popular in a novel production process [7]. Moreover, many studies are carried out on sensors based on nanostructures in the detection and removal of toxins, chemical compounds and other pathogens from food. Some nanosensors are designed to improve food-body assimilation by blocking cholesterol or allergens, which are frequently encountered in groceries [8]. Nanomaterials are also widely tested as constituents in the production of modern functional packaging. Packages enriched by nanostructures are not only stronger but also often become "intelligent" and sometimes they can fix themselves after a slight damage. Changing the package color informs that food is not suitable for consumption because either its expiry date passed or packed edibles started to emit harmful compounds [9].

Recent studies show that nanoparticles can be widely used as heavy-metal detectors. Among others, silver [10,11], gold [12] and also magnetic nanoparticles $[13,14]$ usually doped with other elements (e.g., Ca, Mn) $[15,16]$ have been tested for this purpose. Therefore, detailed studies on adsorption efficiency on doped magnetite nanoparticles are very interesting and innovative in order to understand the importance of core composition and surface modification.

The aim of the study is to examine the efficiency of adsorption of heavy metals in artificial solutions on doped magnetite nanoparticles (Ca, Co, Mn, Ni) surface-modified with PA, SA, AA, 3-PPA or 16-PHDA linkers.

\section{Experimental}

\section{Reagents and solutions}

Chemicals used in this work were of analytical grade and they were used without any purification. $\mathrm{FeCl}_{2} \cdot 4 \mathrm{H}_{2} \mathrm{O}, \mathrm{FeCl}_{3} \cdot 6 \mathrm{H}_{2} \mathrm{O}$, $\mathrm{NH}_{3}$ (25\%), $\mathrm{CaCl}_{2}$ (anhydrous), $\mathrm{MnCl}_{2}$ (anhydrous), $\mathrm{NiCl}_{2}$ (anhydrous), $\mathrm{CuSO}_{4}$ (anhydrous), $\mathrm{PbCl}_{2}$ (anhydrous), $\mathrm{Cd}\left(\mathrm{NO}_{3}\right)_{2} \cdot 4 \mathrm{H}_{2} \mathrm{O}$, and acetic anhydride (AA) were purchased from Polish Chemical Reagents (POCH). $\mathrm{CoCl}_{2}$ (anhydrous), tetrabutylammonium hydroxide ( $\mathrm{TBAOH})(40 \%$ in water), phthalic anhydride (PA), 3-phosphonopropionic acid (3-PPA), 16-phosphonohexadecanoic acid (16-PHDA) and phosphatebuffered saline (PBS) were received from Sigma-Aldrich.

\section{Apparatus}

The structure and morphology of nanoparticles used in the detection experiments were analyzed by X-ray diffraction
(XRD) (Agilent Technologies SuperNova diffractometer with micro-focused Mo K $\alpha_{2}(\lambda=0.713067 \AA)$ radiation and transmission electron microscopy (TEM) (FEI Tecnai G2 X-TWIN $200 \mathrm{kV}$ microscope). For TEM imaging the nanoparticles after dissolution in ethanol were drop-cast on a carbon-covered 400 mesh $\mathrm{Cu}$ grid. The XRD apparatus requires the placement of a small amount of powder on a nylon loop coated with highviscosity synthetic oil. Infrared spectra (IR) were collected in a spectral range between 400 and $4000 \mathrm{~cm}^{-1}$ and were attained by a Nicolet 6700 spectrometer working in transmission mode as a series of 32 repetitive runs. Here, a small amount of powder was directly placed and squeezed into a diamond window for measurement. Mössbauer spectra (MS) were obtained in constant acceleration mode with a ${ }^{57} \mathrm{Co}$ in $\mathrm{Cr}$ matrix source. The spectra were calibrated using $\alpha-\mathrm{Fe}$ foil at room temperature. MS absorbers were prepared by mixing a proper amount of particles with $\mathrm{BN}$ filler to obtain $1 \mathrm{~cm}^{2}$ tablets.

The amount of $\mathrm{Pb}, \mathrm{Cu}$, and $\mathrm{Cd}$ elements in the tested solutions was measured by atomic absorption spectrometry (AAS). Measurements were performed using a high-resolution continuumsource atomic absorption spectrometer ContrAA 700 (Analytik Jena AG, Jena, Germany) equipped with a flame atomizer (burner length: $100 \mathrm{~mm}$ ). The optical system comprises a continuum light source $300 \mathrm{~W}$ high-pressure xenon short-arc lamp XBO 301 (GLE, Berlin, Germany) operating in a "hot-spot" mode, suitable for all the determination of all elements in the wavelength range from 185 to $900 \mathrm{~nm}$. An air-acetylene flame was used for the determination of $\mathrm{Pb}, \mathrm{Cd}$, and $\mathrm{Cu}$ under optimized conditions, namely a) $\mathrm{Pb}$ : burner height: $7 \mathrm{~mm}$, air- $\mathrm{C}_{2} \mathrm{H}_{2}$ flow rate: $75 \mathrm{~L} \cdot \mathrm{h}^{-1}$; b) $\mathrm{Cu}$ : burner height: $4 \mathrm{~mm}$, air- $\mathrm{C}_{2} \mathrm{H}_{2}$ flow rate: $65 \mathrm{~L} \cdot \mathrm{h}^{-1}$; c) $\mathrm{Cd}$ : burner height: $5 \mathrm{~mm}$, air- $\mathrm{C}_{2} \mathrm{H}_{2}$ flow rate: $55 \mathrm{~L} \cdot \mathrm{h}^{-1}$. Absorbance signals of all analytes were obtained using three pixels (central pixel \pm 1 ) for each element. All absorbance values are the mean values based on three repetitive measurements. The dynamic background correction technique with reference was used. The quantitative determination of $\mathrm{Pb}$, $\mathrm{Cd}$, and $\mathrm{Cu}$ was carried out by the external calibration graph technique.

\section{Synthesis of ferrite nanoparticles doped with $\mathrm{Ca}^{2+}$, $\mathrm{Co}^{2+}, \mathrm{Mn}^{2+}$, or $\mathrm{Ni}^{2+}$}

To obtain doped ferrite nanoparticles, a modified co-precipitation synthesis of iron(II) and iron(III) chlorides was used [1719]. As a reference, pure magnetite nanoparticles were also synthesized by the method described below.

In the first step of the synthesis, into each of two three-necked flasks, $0.5 \% \mathrm{NH}_{3}$ solution was placed and deoxygenated with argon for $20 \mathrm{~min}$. Then, TBAOH was injected to each flask and one solution was heated and stirred $\left(40^{\circ} \mathrm{C}, 20 \mathrm{~min}\right)$ while the 
other one was deoxygenated at room temperature. In the next step, a proper amount of $\mathrm{FeCl}_{3} \cdot 6 \mathrm{H}_{2} \mathrm{O}$ was added to the heated up flask, and $\mathrm{FeCl}_{2} \cdot 4 \mathrm{H}_{2} \mathrm{O}$ to the other one. After $15 \mathrm{~min}, \mathrm{FeCl}_{2}$, $\mathrm{CaCl}_{2}, \mathrm{CoCl}_{2}, \mathrm{MnCl}_{2}$, or $\mathrm{NiCl}_{2}$, were additionally added to the second flask in respective amounts. The resultant solution was finally poured into the flask with $\mathrm{FeCl}_{3} \cdot 6 \mathrm{H}_{2} \mathrm{O}$, and the whole mixture was kept at $80{ }^{\circ} \mathrm{C}$ for $40 \mathrm{~min}$. Thereafter, the solution was cooled down, removed from the supernatant and washed with deoxygenated acetone. Rinsing was repeated two more times and, finally, the sample was dried by rotary evaporation until a powder was obtained [20,21].

\section{Modification of nanoparticles with phthalic an- hydride, succinic anhydride and acetic anhydride}

The application of $\mathrm{Ca}$ ferrite nanoparticles modified with $\mathrm{SiO}_{2}$ and phthalic anhydride for the detection of $\mathrm{Pb}$ in water and food products was described in the literature [15]. The role of the selected inorganic core, however, was not discussed. The modified nanoparticles used in this study had a selectivity for $\mathrm{Pb}$ ions twice of that for other metals. In this paper, we will compare the efficiency of PA with other proposed linkers. For this purpose, every type of prepared ferrite nanoparticles was modified with PA, SA and AA. For the modification solutions of PA, SA or
AA in ethanol with a concentration of $100 \mathrm{mM}$ were added to about $8 \mathrm{mg}$ of nanoparticles and stirred for $4 \mathrm{~h}$ at room temperature. Then, the functionalized nanoparticles were separated from the solutions using a permanent magnet, washed three times with ethanol and left overnight for drying.

\section{Modification of nanoparticles with 3-PPA and 16-PHDA}

Another group of compounds tested and selected for the studies as potential heavy-metal detectors are 3-phosphonopropionic acid (3-PPA) and 16-phosphonohexadecanoic (16-PHDA). Before the modification with 3-PPA or 16-PHDA, nanoparticles were washed firstly in acetone and then ethanol, and placed for about $30 \mathrm{~s}$ in an ultrasonic bath to ensure proper particles separation. In the next step, $1 \mathrm{~mL}$ of $1 \mathrm{mM}$ solution of 3-PPA or 16-PHDA, respectively, were added to the nanoparticles and left at room temperature for $18 \mathrm{~h}$. After this time the mixture was placed in an ultrasonic bath for $1 \mathrm{~min}$, then the supernatant was removed and the nanoparticles were washed three times with PBS and allowed to dry at room temperature [22]. Figure 1A presents the proposed most probable models of linker adsorption. However, the authors do not exclude other configurations.

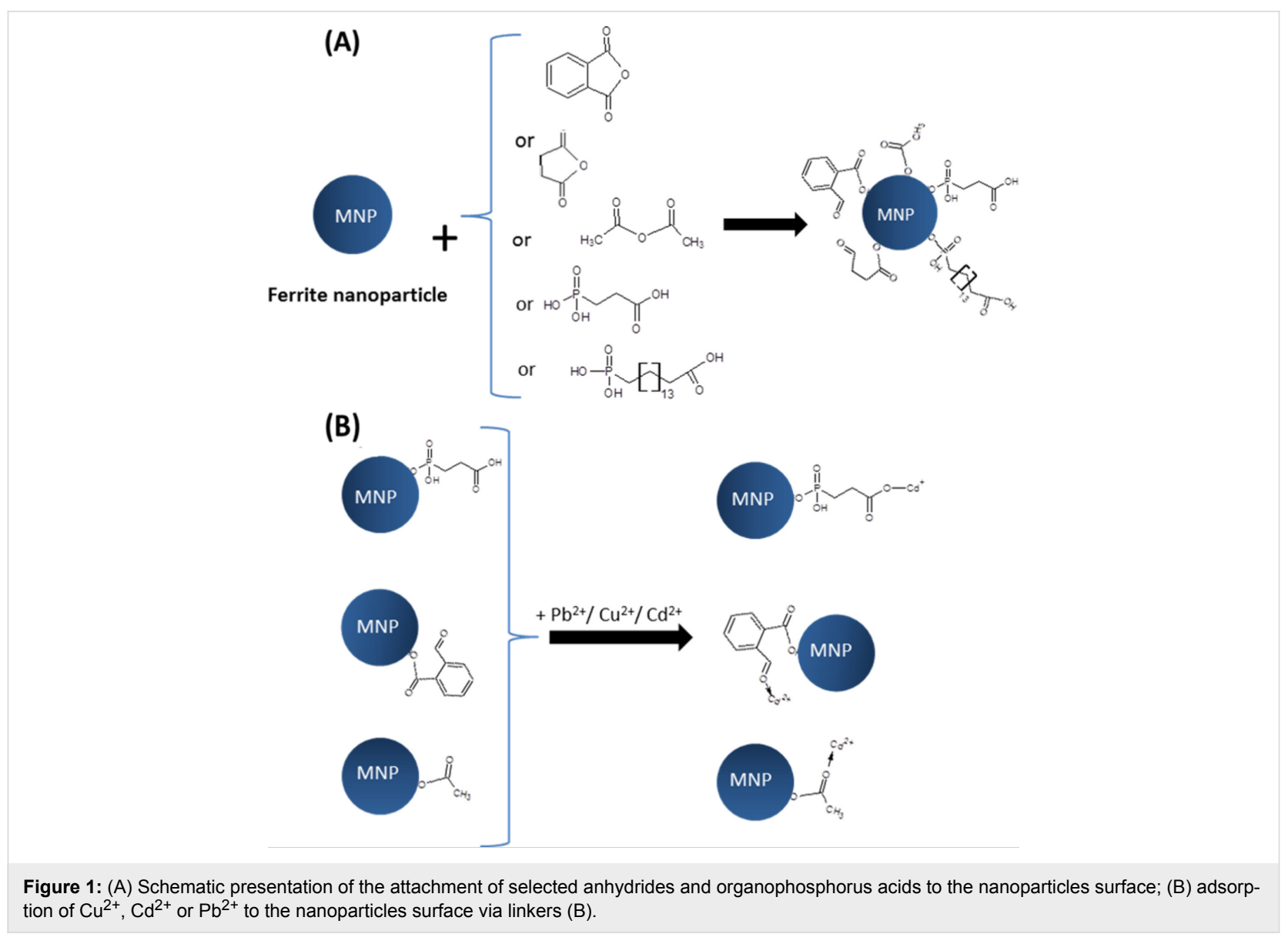




\section{Attachment of $\mathrm{Pb}^{2+}, \mathrm{Cu}^{2+}$ and $\mathrm{Cd}^{2+}$ ions}

In order to verify if modified nanoparticles are able to detect/ select some ions from liquids, aqueous model solutions were prepared. The solutions and particles were analyzed by IR spectroscopy, EDX and AAS measurements after the tests.

For this purpose, approx. $8 \mathrm{mg}$ of surface-modified nanoparticles were added to a $0.1 \mathrm{M}$ aqueous solution of $\mathrm{Pb}^{2+}, \mathrm{Cu}^{2+}$ and $\mathrm{Cd}^{2+}$. This mixture was stirred for $10 \mathrm{~min}$ by a magnetic stirrer. After this time, the liquid was removed and analyzed by AAS to determine the amount of remaining elements. Nanoparticles were left to dry for $4 \mathrm{~h}$ at room temperature. A proposed scheme for the binding of heavy metal ions is presented in Figure 1B.

\section{Results and Discussion Transmission electron microscopy}

Prior to any modification of the nanoparticles, their morphology and structural quality was determined. The most informative method is transmission electron microscopy, by which the morphology of the prepared ferrite nanoparticles was analyzed before surface modification. The obtained images for each kind of fabricated ferrites are presented in Figure 2.

The TEM images show that regardless of doping $\left(\mathrm{Ca}^{2+}, \mathrm{Co}^{2+}\right.$, $\mathrm{Mn}^{2+}$ or $\mathrm{Ni}^{2+}$ ), the studied nanoparticles exhibit a similar round shape and average size. In Table 1, diameters of every type of synthesized nanoparticles estimated from TEM images are collected. The obtained average particle sizes are close to those calculated for pure magnetite nanoparticles, which implies that proposed ions do not disturb the crystallization process and used synthesis constituents fulfill the same growth regimes [23].

\section{X-ray diffraction}

The fabrication of nonstochiometric compounds affects crystal growth, which is reflected in the crystalization degree. Therefore, examination of the crystallinity of the ferrite nanoparticles was performed by X-ray diffraction. The presence of welldefined sharp patterns proves the incorporation of $\mathrm{Ca}, \mathrm{Co}, \mathrm{Mn}$ and $\mathrm{Ni}$ elements into the primary magnetite structure. The obtained diffractograms are depicted in Figure 3.

The XRD patterns show peaks typical for magnetite regardless of the nature of added elements. The $2 \theta$ values and the relative intensities unequivocally state the presence of dominate magnetite phase. The most intense reflexes were recognized and indexed to (220), (311), (400), (422), (511), (440), respectively, typical for magnetite [24]. The peak widths, however, are different among the presented samples. This can be caused by chemical modification of the crystallites related to the different ionic radii of the added elements and a resulting slight distortion of the crystal phase. Substitution can take place as a random distribution of particular atoms or as ordered process. Such changes in the structure will cause different modifications of the XRD patterns. The estimation of an average diffraction zone which is related to the crystal size and, therefore, the parti-
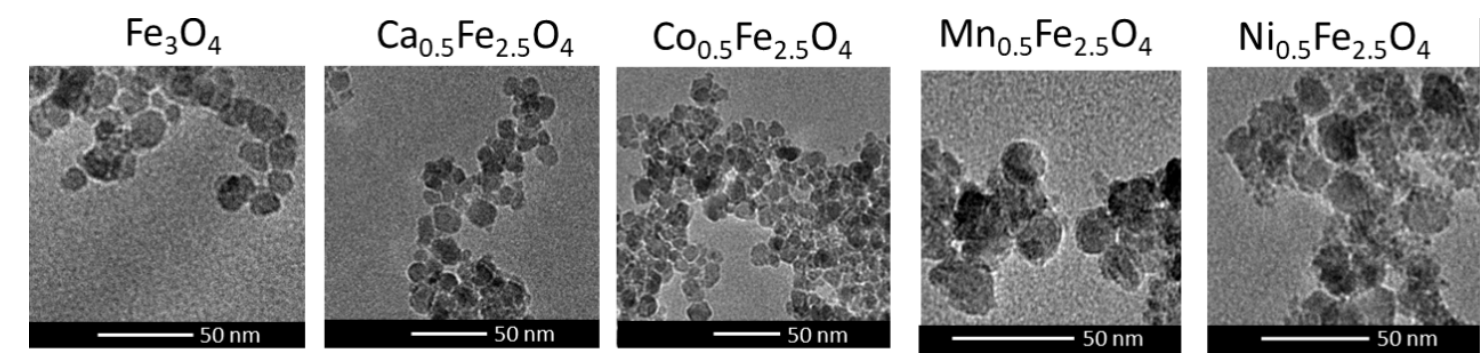

Figure 2: TEM images of prepared ferrite nanoparticles.

Table 1: Table with average crystallite sizes of ferrite nanoparticles estimated from TEM images sizes and calculated from the XRD data

\begin{tabular}{lll} 
type of nanoparticles & nanoparticle size [nm] (TEM) & average crystallite size [nm] (XRD) \\
\hline $\mathrm{Fe}_{3} \mathrm{O}_{4}$ & $13 \pm 2$ & $13 \pm 2$ \\
$\mathrm{Ca}_{0.5} \mathrm{Fe}_{2.5} \mathrm{O}_{4}$ & $10 \pm 2$ & $13 \pm 2$ \\
$\mathrm{Co}_{0.5} \mathrm{Fe}_{2.5} \mathrm{O}_{4}$ & $13 \pm 2$ & $13 \pm 2$ \\
$\mathrm{Mn}_{0.5} \mathrm{Fe}_{2.5} \mathrm{O}_{4}$ & $12 \pm 2$ & $10 \pm 2$ \\
$\mathrm{Ni}_{0.5} \mathrm{Fe}_{2.5} \mathrm{O}_{4}$ & $14 \pm 2$ & $12 \pm 2$
\end{tabular}




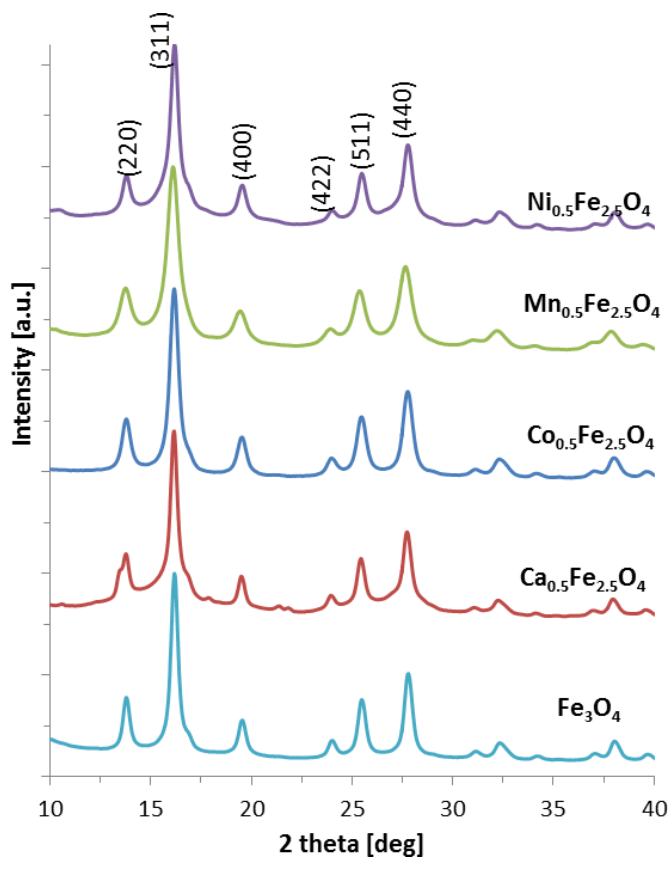

Figure 3: XRD patterns of ferrite nanoparticles.

cle diameter can be calculated by the Scherrer equation (Equation 1). The obtained values are given together with TEM values in Table 1.

$$
D=\frac{0.9 \lambda}{B_{1 / 2} \cdot \cos \theta},
$$

where $D$ is the grain size $[\AA], \lambda$ is the wavelength (here $0.7136 \AA), B_{1 / 2}$ is the full width at half maximum intensity of the (311) peak [rad], and $\Theta$ is the diffraction angle [rad]. The average crystallite sizes of nanoparticles presented in Table 1 are similar to each other within the error margin. At the same time, the obtained results of the average grain size estimated on the basis of the TEM images agree with the values calculated from XRD. A numerical analysis of XRD patterns also allows for the assessment of crystal cell parameters, which can be found in Table 2. There, literature bulk values are compared with our findings and both are in satisfactory agreement, which also confirms the successful fabrication of requested structures.

\begin{tabular}{|c|c|c|}
\hline & theoretical $[\AA]$ & $\begin{array}{l}\text { experimental }[\AA] \\
\pm 0.05\end{array}$ \\
\hline $\mathrm{y}-\mathrm{Fe}_{2} \mathrm{O}_{3}$ & 8.34 & 8.36 \\
\hline $\mathrm{Fe}_{3} \mathrm{O}_{4}$ & 8.39 & \\
\hline $\mathrm{Ca}_{0.5} \mathrm{Fe}_{2.5} \mathrm{O}_{4}$ & - & 8.37 \\
\hline $\mathrm{Co}_{0.5} \mathrm{Fe}_{2.5} \mathrm{O}_{4}$ & 8.38 & 8.43 \\
\hline $\mathrm{Mn}_{0.5} \mathrm{Fe}_{2.5} \mathrm{O}_{4}$ & 8.51 & 8.40 \\
\hline $\mathrm{Ni}_{0.5} \mathrm{Fe}_{2.5} \mathrm{O}_{4}$ & 8.33 & 8.36 \\
\hline
\end{tabular}

\section{Infrared spectroscopy}

All samples were measured by IR spectroscopy to see if the surface of nanoparticles changes after core modification and surface functionalization. This method was also expected to serve as a reference for the detection of heavy metals. However, the obtained results show that it is not sufficient in every case. Selected results of modified $\mathrm{Mn}_{0.5} \mathrm{Fe}_{2.5} \mathrm{O}_{4}$ with different linkers and after the detection of $\mathrm{Cd}^{2+}, \mathrm{Cu}^{2+}$ or $\mathrm{Pb}^{2+}$ are presented in Figure 4. This core composition was selected as representative sample for the following tests. Nevertheless, all types of particles were analyzed in the same way.
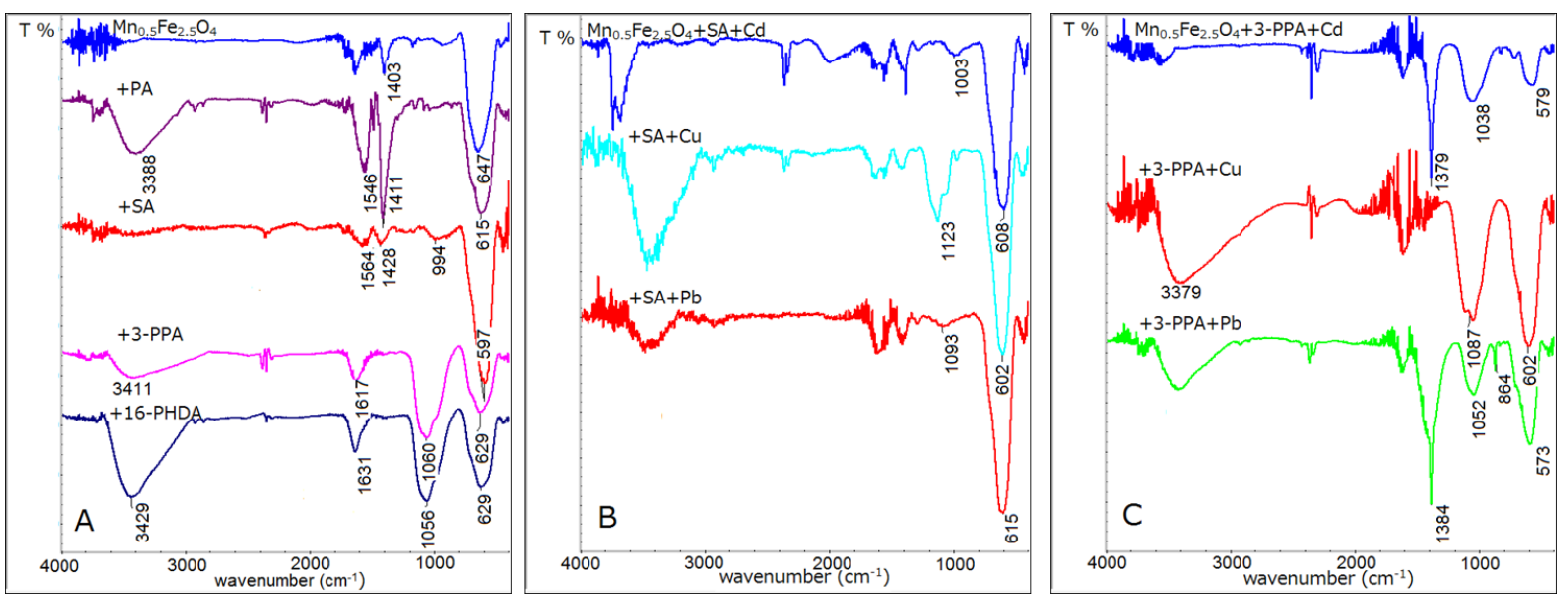

Figure 4: The IR spectra of $\mathrm{Mn}_{0.5} \mathrm{Fe}_{2.5} \mathrm{O}_{4}$ nanoparticles $\mathrm{A}$ ) with various linkers used in the experiment, $\mathrm{B}$ ) with attached $\mathrm{SA}$ and $\mathrm{Cd}$, $\mathrm{Cu}$ and $\mathrm{Pb}$; and C) with attached 3-PPA and $\mathrm{Cd}$, $\mathrm{Cu}$ and $\mathrm{Pb}$. 
Figure 4A shows the IR spectra of ferrite nanoparticles before and after linker modification. It can be seen that spectra after modification with PA and SA have increased signals (in comparison to unmodified one) in the range of $1393-1591 \mathrm{~cm}^{-1}$, which indicates the presence of $\mathrm{C}-\mathrm{C}$ bonds in the rings of $\mathrm{PA}$ and SA [30]. The spectra after functionalization with 3-PPA or 16-PHDA show the presence of signals around 1060 and $1105 \mathrm{~cm}^{-1}$, which proves the presence of $\mathrm{P}-\mathrm{O}$ and $\mathrm{P}-\mathrm{O}-\mathrm{Fe}$ stretching bonds [31]. Bands at $650-590 \mathrm{~cm}^{-1}$ are typical for $\mathrm{Fe}-\mathrm{O}$ in magnetite/maghemite [32]. This observation confirms a successful modification of the surface of the nanoparticles. The spectra in Figure 4B were collected after the exposition of nanoparticles modified with $\mathrm{SA}$ to $\mathrm{Cd}, \mathrm{Cu}$ and $\mathrm{Pb}$ ions. As a result, signals in the range of $1003-1123 \mathrm{~cm}^{-1}$ appear in addition to those previously observed. In the last series (Figure 4C) the presence of sharp signals at $1379-1384 \mathrm{~cm}^{-1}$ in case of Cd and $\mathrm{Pb}$ attachment can be found. In this region modifications in the reference system were also observed after interaction with heavy metal [15]. Therefore, the origin of these signals is most probable due to heavy ion adsorption. However, due to a lack of reference information, it is the only speculation on the origin of appearing new signals.

\section{Raman spectroscopy}

After every step (synthesis, surface modification, and heavy metal attachment) powdered samples of nanoparticles were analyzed using Raman spectroscopy giving additional information to IR spectroscopy. In Figure 5 selected spectra are presented.

The Raman spectra show a set of peaks that are typical for inorganic cores (magnetite, maghemite/hematite) with accordingly modified organic shells. In Figure 5A only spectra of unmodi- fied particles are collected. One can see that these spectra are dominated by signals centered around $600-700 \mathrm{~cm}^{-1}$. This signal can be attributed both to magnetite and maghemite. The position closer to the middle value of $673-683 \mathrm{~cm}^{-1}$ suggests a magnetite-dominated contribution to the signal, while deviation to lower or higher values indicates more maghemite-like contributions [33]. The presence of signals below $670 \mathrm{~cm}^{-1}$ implies surface oxidation to maghemite or hematite (for details see Table 3). Signals at a wave number higher than $700 \mathrm{~cm}^{-1}$ indicate the presence of an organic shell. Co-doped ferrite nanoparticles have an evidentially dominating peak moved to $600 \mathrm{~cm}^{-1}$, which is in good agreement with the doublet observed in Mössbauer spectra, which, in turn, suggests the presence of maghemite. Ni ferrite also shows a similar trend, which is a hint that local Fe surrounding becomes maghemite-like.

$\begin{aligned} & \text { Table 3: Positions of the most intensive lines in the Raman spectra of } \\
& \text { tested samples [34]. }\end{aligned}$
\begin{tabular}{ll} 
peak position $\left[\mathrm{cm}^{-1}\right]$ & assignment \\
\hline $524,673-683$ & $\mathrm{Fe}_{3} \mathrm{O}_{4}$ \\
$322-335,704-715$ & $\mathrm{~V}^{-}-\mathrm{Fe}_{2} \mathrm{O}_{3}$ \\
224,604 & $\alpha-\mathrm{Fe}_{2} \mathrm{O}_{3}$ \\
$1335-1383$ & $\mathrm{C}-\mathrm{C}$ aliphatic chain $/ \mathrm{Y}-\mathrm{Fe}_{2} \mathrm{O}_{3}$ \\
$1049,1166,1415,1585$ & $\mathrm{C}-\mathrm{C}$, aromatic ring chain \\
& vibrations
\end{tabular}

In Figure 5B, the spectra of SA-modified $\mathrm{Mn}_{0.5} \mathrm{Fe}_{2.5} \mathrm{O}_{4}$ nanoparticles after the adsorption of different ions are depicted. The comparison of spectra collected in Figure 5B with unmodified particles (Figure $5 \mathrm{~A}$ ) indicates that surface functionalization by SA causes the presence of a band at $1592 \mathrm{~cm}^{-1}$, and that the
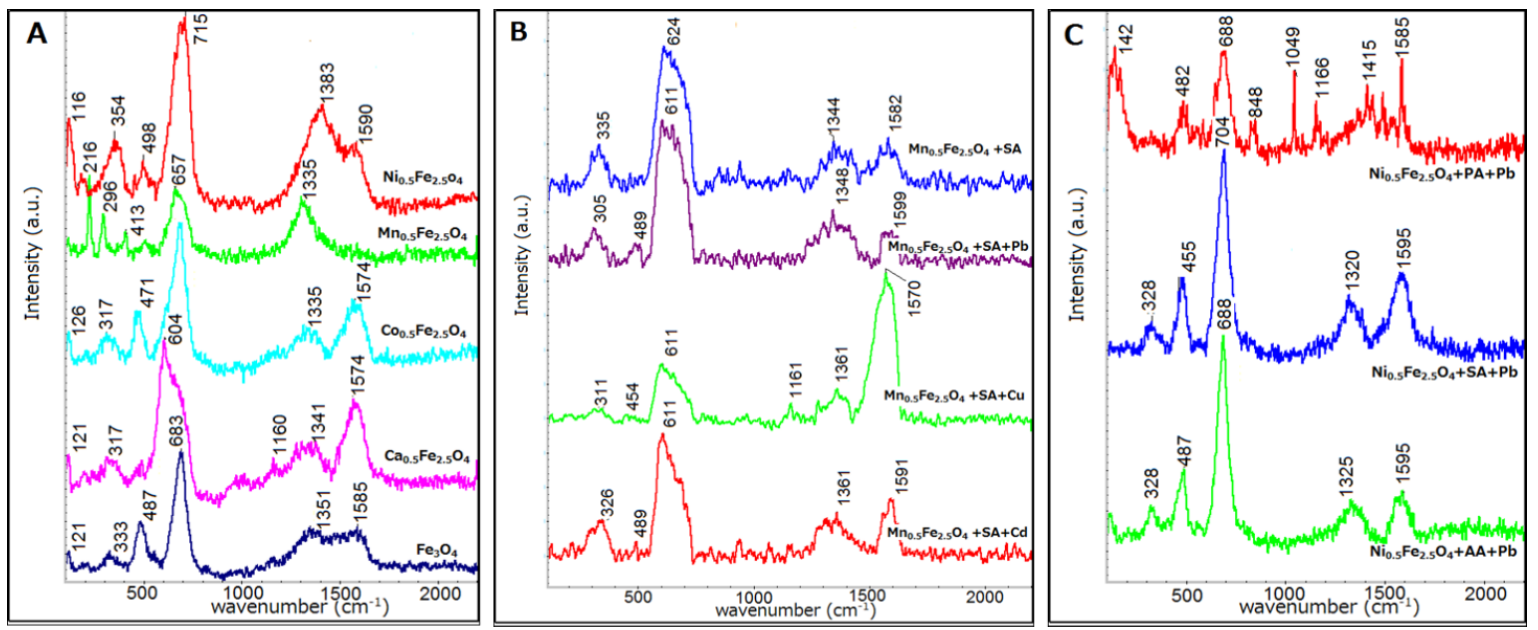

Figure 5: Raman spectra of A) ferrite nanoparticles; B) SA-modified nanoparticles with attached heavy-metal ions; C) various anhydride-modified nanoparticles with attached $\mathrm{Pb}$ ions. 
adsorption of heavy-metal ions causes further alternation of the signals in the range of $1200-1700 \mathrm{~cm}^{-1}$, which is connected to the interaction of the metal ions with SA and the nanoparticles. A shift of IR signals after heavy-metal adsorption was reported previously [15].

Figure 5C shows the modulation of Raman spectra by different compounds at the surface. A number of additional bands seen in case of PA are due to its specific chemical structure (Table 3). Considering all above-mentioned findings, Raman spectroscopy confirms the surface modification of the nanoparticles and the attachment of heavy-metal ions.

\section{Mössbauer spectroscopy}

The magnetic properties of obtained ferrite nanoparticles were examined by Mössbauer spectroscopy at room temperature. The obtained spectra are presented in Figure 6. All spectra show mostly the same features. The first one is the presence of a sextet with broadened lines, which is actually a superposition of sextets corresponding to $\mathrm{Fe}$ atoms at the $\mathrm{A}$ and $\mathrm{B}$ sites of the magnetite structure [35]. The broadening depends on the type of dopant atoms. In the case of Co ions, the full width at half maximum of the spectral lines is much smaller than in the other cases. An especially wide spectrum is observed in the case of magnetite doped by Mn atoms. The value of the average hyperfine magnetic field on the iron atoms is highest on the sample with Co dopant. The second characteristic feature is the presence of a doublet in the central part of the spectrum, which is connected to the superparamagnetic behavior of Fe magnetic moments in the studied samples. The relative intensity of the doubles depends on the kind of dopant. The most intensive doublet is observed for magnetite doped by $\mathrm{Ca}$ (more than 50\%) and the smallest one in the case of Co dopant. These results show that the superparamagnetic blocking temperature for the $\mathrm{Ca}$ doping is below room temperature whereas for the other cases it is slightly above. Taking both features of the measured spectra into account, the mean values of the hyperfine field are equal to $43 \mathrm{~T}, 44 \mathrm{~T}, 39 \mathrm{~T}, 30 \mathrm{~T}$ and $20 \mathrm{~T}$ for pure magnetite and Co-, Ni-, Mn- and Ca-doped magnetite, respectively. This value strongly depends on the ferrite composition, particle size, surface modification and proximity to superparamagnetic blocking temperature.

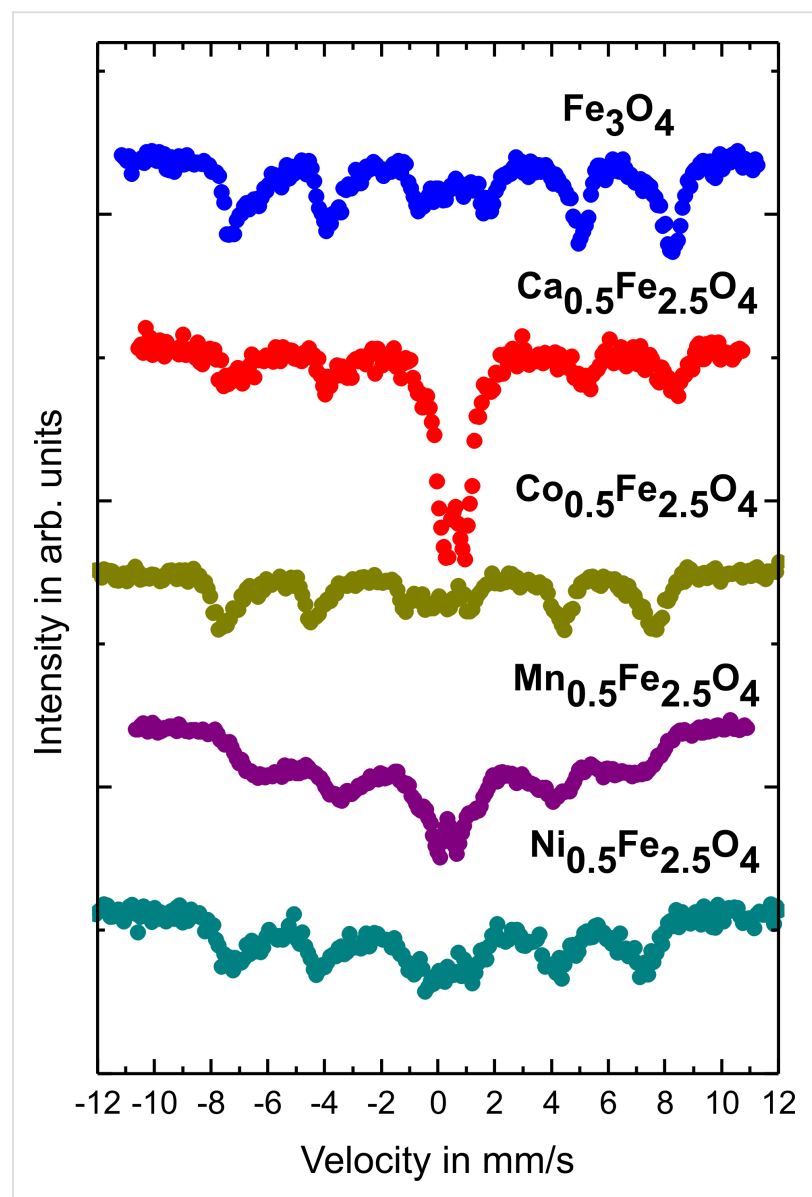

Figure 6: Mössbauer spectra of $\mathrm{Fe}_{3} \mathrm{O}_{4}, \mathrm{Ca}_{0.5} \mathrm{Fe}_{2.5} \mathrm{O}_{4}, \mathrm{Co}_{0.5} \mathrm{Fe}_{2.5} \mathrm{O}_{4}$, $\mathrm{Mn}_{0.5} \mathrm{Fe}_{2.5} \mathrm{O}_{4}$ and $\mathrm{Ni}_{0.5} \mathrm{Fe}_{2.5} \mathrm{O}_{4}$ nanoparticles.
Cd

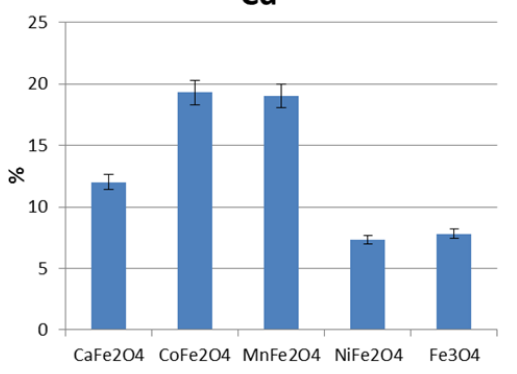

$\mathrm{Cu}$

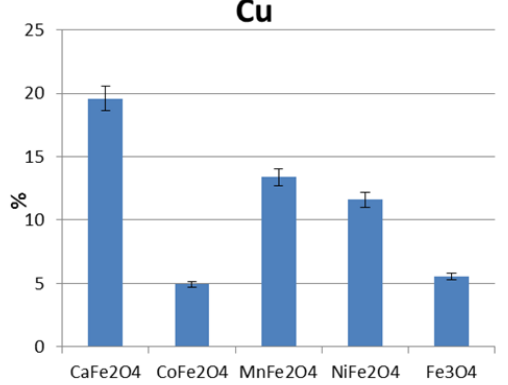

$\mathrm{Pb}$

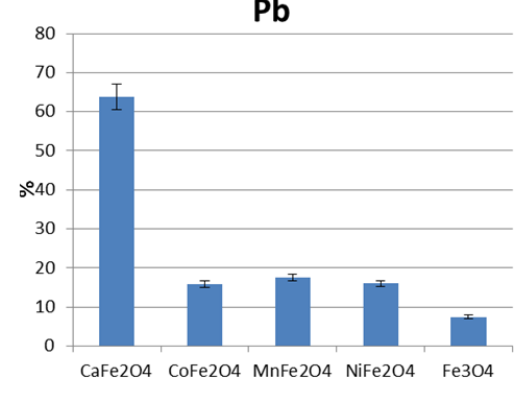




\section{Attachment of $\mathrm{Cu}^{2+}, \mathrm{Cd}^{2+}$ and $\mathrm{Pb}^{2+}$ ions to unmodified nanoparticles}

In the first attempt, we have tested the effectiveness of attachment of metal ions to the unmodified surface of the nanoparticles. This test gives us a reference value and shows if inorganic core additional functionalization affects the interaction with ions. Therefore, ferrite nanoparticles were added to the aqueous heavy-metal solutions and stirred. The liquids were separated from the solid particles, which were dried at room temperature. Powdered samples after the adsorption experiment were examined by EDX and the results are given in Figure 7.

It can be seen that pure magnetite has the lowest capability of interaction with the tested ions. $\mathrm{Mn}_{0.5} \mathrm{Fe}_{2.5} \mathrm{O}_{4}$ and $\mathrm{Co}_{0.5} \mathrm{Fe}_{2.5} \mathrm{O}_{4}$ nanoparticles have a similar adsorption tendency of about $20 \%$ in case of $\mathrm{Cd}$ and $\mathrm{Pb}$ ions. Ni ferrite has an adsorption efficiency for $\mathrm{Pb}$ similar to that of the previous ferrites, but a very low adsorption efficiency for $\mathrm{Cd}^{2+}$. In case of $\mathrm{Cu}^{2+}$, the situation is different. Here, $\mathrm{Mn}_{0.5} \mathrm{Fe}_{2.5} \mathrm{O}_{4}$ and $\mathrm{Ni}_{0.5} \mathrm{Fe}_{2.5} \mathrm{O}_{4}$ show similar values of about $12 \%$, while $\mathrm{Co}_{0.5} \mathrm{Fe}_{2.5} \mathrm{O}_{4}$ exhibits the worst performance. Interestingly, $\mathrm{Ca}$ ferrite adsorbs the most $\mathrm{Pb}^{2+}$ up to more than $60 \%$. It seems that $\mathrm{Mn}_{0.5} \mathrm{Fe}_{2.5} \mathrm{O}_{4}$ has the most similar adsorption properties regarding all types of heavy metals. Hence, for further examination nanoparticles doped with $\mathrm{Mn}$ were used. Other ferrite particles will be a subject of further studies (not presented here).

\section{Adsorption of $\mathrm{Cu}, \mathrm{Cd}$, and $\mathrm{Pb}$ on nanoparti- cles with modified surfaces}

Aqueous solutions of $\mathrm{Cu}, \mathrm{Cd}$, or $\mathrm{Pb}$ were prepared and added to the nanoparticles. The mixtures were vigorously mixed on a magnetic stirrer. Then, nanoparticles were removed and the concentrations of $\mathrm{Cu}, \mathrm{Cd}$, or $\mathrm{Pb}$ in the obtained solutions were analyzed using AAS. The data collected in Table 4 show the percentage values of adsorbed heavy-metal ions. It indicates that the best and most universal linker enhancing the adsorption of heavy-metal ions is SA. The PA linker is not selective for $\mathrm{Cu}$

Table 4: Percentage of ions adsorbed by $\mathrm{Mn}_{0.5} \mathrm{Fe}_{2.5} \mathrm{O}_{4}$ nanoparticles modified with different linkers measured by AAS. As a reference, unmodified nanoparticles were used.

\begin{tabular}{llll} 
& \multicolumn{3}{c}{ percentage of ions adsorbed } \\
& $\mathrm{Pb}$ & $\mathrm{Cu}$ & $\mathrm{Cd}$ \\
\hline $\mathrm{NPs}$ & $26.1 \pm 0.2$ & $22.9 \pm 0.2$ & $6.5 \pm 0.2$ \\
$\mathrm{NPs}+\mathrm{PA}$ & $36.8 \pm 0.2$ & $3.2 \pm 0.2$ & $27.5 \pm 0.2$ \\
$\mathrm{NPs}+\mathrm{SA}$ & $38.1 \pm 0.2$ & $23.8 \pm 0.2$ & $32.3 \pm 0.2$ \\
$\mathrm{NPs}+\mathrm{AA}$ & $15.9 \pm 0.2$ & $14.4 \pm 0.2$ & $12.1 \pm 0.2$ \\
$\mathrm{NPs}+$ 3-PPA & $25.7 \pm 0.2$ & $12.3 \pm 0.2$ & $14.9 \pm 0.2$ \\
$\mathrm{NPs}+$ 16-PHDA & $1.9 \pm 0.2$ & $11.8 \pm 0.2$ & $7.6 \pm 0.2$
\end{tabular}

ions, but rather good for $\mathrm{Pb}$ and $\mathrm{Cd}$. We are aware that adsorption efficiency can be tuned by many other parameters, for example such as linker concentration, heavy ions concentration, $\mathrm{pH}$ value, or inorganic core composition, and such studies are in progress and will be a subject of subsequent papers.

\section{Conclusion}

Ferrite nanoparticles doped with calcium, cobalt, nickel, or manganese show differences in ion adsorption depending on the type of core. This indicates that the strength of the interparticle interaction can be one of the parameters governing the adsorption capability. It has been confirmed that calcium-modified ferrite is the most effective in $\mathrm{Pb}$ case, but only when the core is modified by PA. In any other case its role is average. IR measurements have proved a successful connection of the tested linkers to all nanoparticles, which entails that particles become a proper platform to further studies. AAS tests clearly confirmed the attachment of heavy metals to the selected nanoparticles $\left(\mathrm{Mn}_{0.5} \mathrm{Fe}_{2.5} \mathrm{O}_{4}\right)$, with variable efficiency depending on the type of ions. SA appears to be the most effective and universal linker. The use of other types of compounds such as 3-PPA or 16-PHDA improved adsorption in selected cases, but they are not as versatile as succinic anhydride. Other anhydrides (PA and AA) also improve the adsorption of heavy metals in comparison to unmodified particles, but not as efficiently as SA. To conclude, succinic anhydride may be a good potential modifier of the $\mathrm{Mn}_{0.5} \mathrm{Fe}_{2.5} \mathrm{O}_{4}$ particles to enhance the selective adsorption of heavy metal ions from aqueous solutions. Therefore, in future, experiments with real food samples or a richer solution matrix will be performed. The adsorption efficiency strongly depends on core composition as well as surface modification, and only a complex analysis of the system allows one to draw adequate conclusions.

\section{Acknowledgements}

Mössbauer spectroscopy was performed in close collaboration with the Department of Physics of the University of Bialystok. The work was partially financed by the EU funds via the project with a contract number POPW.01.03.00-20-034/09-00, POPW.01.03.00-20-004/11-00, and by NCN funds 2014/13/N/ ST5/00568.

\section{ORCID ${ }^{\circledR}$ iDs}

Elżbieta Zambrzycka-Szelewa - https://orcid.org/0000-0002-1164-4747

\section{References}

1. Akbarzadeh, A.; Samiei, M.; Davaran, S. Nanoscale Res. Lett. 2012, 7, 144. doi:10.1186/1556-276X-7-144

2. Singh, R.; Lillard, J. W., Jr. Exp. Mol. Pathol. 2009, 86, 215-223. doi:10.1016/j.yexmp.2008.12.004 
3. Feng, L.; Cao, M.; Ma, X.; Zhu, Y.; Hu, C. J. Hazard. Mater. 2012, 217-218, 439-446. doi:10.1016/j.jhazmat.2012.03.073

4. Laurent, S.; Forge, D.; Port, M.; Roch, A.; Robic, C.; Vander Elst, L.; Muller, R. N. Chem. Rev. 2008, 108, 2064-2110. doi:10.1021/cr068445e

5. Sharifpour, E.; Khafri, H. Z.; Ghaedi, M.; Asfaram, A.; Jannesar, R. Ultrason. Sonochem. 2018, 40, 373-382. doi:10.1016/j.ultsonch.2017.07.030

6. Gaikwad, K. K. Active and Intelligent Packaging: Future Need. In Food Processing and technology: New emerging areas; Bhatt, D. K.; Kumar, S., Eds.; Shree Publishers \& Distributors: New Delhi, 2014.

7. Mason, T. G.; Graves, S. M.; Wilking, J. N.; Lin, M. Y. Condens. Matter Phys. 2006, 9, 193-199. doi:10.5488/CMP.9.1.193

8. Berekaa, M. M. Int. J. Curr. Microbiol. Appl. Sci. 2015, 4, 345-357.

9. The Role of Packaging in Minimising Food Waste in the Supply Chain of the Future. http://mams.rmit.edu.au/ie9rn2ifqca.pdf (accessed Jan 30, 2018).

10. Hung, Y.-L.; Hsiung, T.-M.; Chen, Y.-Y.; Huang, Y.-F.; Huang, C.-C. J. Phys. Chem. C 2010, 114, 16329-16334. doi:10.1021/jp1061573

11. Maiti, S.; Barman, G.; Konar Laha, J. Appl. Nanosci. 2016, 6, 529-538. doi:10.1007/s13204-015-0452-4

12. Sugunan, A.; Thanachayanont, C.; Dutta, J.; Hilborn, J. G. Sci. Technol. Adv. Mater. 2005, 6, 335-340. doi:10.1016/j.stam.2005.03.007

13. Predescu, A.; Matei, E.; Berbecaru, A.; Vidu, R. Synthesis of Magnetic Nanoparticles for the Removal of Heavy Metal lons from Wastewaters. In Proceedings of the 38th Annual Congress of the American Romanian Academy of Arts and Sciences, Pasadena, CA, USA, July 23-27, 2014; ARA Publisher, 2014; pp 37-42.

14. Dil, E. A.; Ghaedi, M.; Asfaram, A.; Mehrabi, F. Ultrason. Sonochem. 2017, 36, 409-419. doi:10.1016/j.ultsonch.2016.12.016

15. Pirouz, M. J.; Beyki, M. H.; Shemirani, F. Food Chem. 2015, 170, 131-137. doi:10.1016/j.foodchem.2014.08.046

16. Kong, J.; Coolahan, K.; Mugweru, A. Anal. Methods 2013, 5, 5128. doi:10.1039/c3ay40359a

17. Kalska-Szostko, B.; Wykowska, U.; Piekut, K.; Zambrzycka, E. Colloids Surf., A 2013, 416, 66-72. doi:10.1016/j.colsurfa.2012.10.019

18. Kandpal, N. D.; Sah, N.; Loshali, R.; Joshi, R.; Prasad, J. J. Sci. Ind. Res. 2014, 73, 87-90.

19. Kalska-Szostko, B.; Kropiewnicka, K. Curr. Appl. Phys. 2012, 12, 896-902. doi:10.1016/j.cap.2011.12.003

20. Satuła, D.; Kalska-Szostko, B.; Szymański, K.; Dobrzyński, L.; Kozubowski, J. Acta Phys. Pol., A 2008, 114, 1615-1621. doi:10.12693/APhysPolA.114.1615

21. Kalska-Szostko, B.; Wykowska, U.; Satula, D.; Nordblad, P. Beilstein J. Nanotechnol. 2015, 6, 1385-1396. doi:10.3762/bjnano.6.143

22. Kalska-Szostko, B.; Rogowska, M.; Satuła, D. Colloids Surf., B 2013, 111, 656-662. doi:10.1016/j.colsurfb.2013.07.004

23. Krishnan, K. M. Fundamentals and Applications of Magnetic Materials; Oxford University Press, 2016. doi:10.1093/acprof:oso/9780199570447.001.0001

24. Mahadevan, S.; Gnanaprakash, G.; Philip, J.; Rao, B. P. C.; Jayakumar, T. Physica E 2007, 39, 20-25. doi:10.1016/j.physe.2006.12.041

25. Blaney, L., "Magnetite $\left(\mathrm{Fe}_{3} \mathrm{O}_{4}\right)$ : Properties, Synthesis, and Applications". http://preserve.lehigh.edu/cas-lehighreview-vol-15/5 (accessed Jan 30, 2018).

26. Goss, C. J. Phys. Chem. Miner. 1988, 16, 164-171.
27. Thang, P. D.; Rijnders, G.; Blank, D. H. A. J. Magn. Magn. Mater. 2005, 295, 251-256. doi:10.1016/j.jmmm.2005.01.011

28. Farooq, H.; Ahmad, M. R.; Jamil, Y.; Hafeez, A.; Mahmood, Z.; Mahmood, T. J. Basic Appl. Sci. 2012, 8, 597-601. doi:10.6000/1927-5129.2012.08.02.53

29. Nabiyouni, G.; Jafari Fesharaki, M.; Mozafari, M.; Amighian, J. Chin. Phys. Lett. 2010, 27, 126401. doi:10.1088/0256-307X/27/12/126401

30. Coates, J. Interpretation of Infrared Spectra, A Practical Approach. Encyclopedia of Analytical Chemistry; Wiley, 2006. doi:10.1002/9780470027318.a5606

31. Kalska-Szostko, B.; Orzechowska, E.; Wykowska, U. Colloids Surf., B 2013, 111, 509-516. doi:10.1016/j.colsurfb.2013.05.033

32. Subramanian, N. D.; Moreno, J.; Spivey, J. J.; Kumar, C. S. S. R. J. Phys. Chem. C 2011, 115, 14500-14506. doi:10.1021/jp202215k

33. Slavov, L.; Abrashev, M. V.; Merodiiska, T.; Gelev, C.; Vandenberghe, R. E.; Markova-Deneva, I.; Nedkov, I. J. Magn. Magn. Mater. 2010, 322, 1904-1911. doi:10.1016/j.jmmm.2010.01.005

34. Chourpa, I.; Douziech-Eyrolles, L.; Ngaboni-Okassa, L.; Fouquenet, J.-F.; Cohen-Jonathan, S.; Soucé, M.; Marchais, H.; Dubois, P. Analyst 2005, 130, 1395-1403. doi:10.1039/b419004a

35. Kalska-Szostko, B.; Satuła, D.; Olszewski, W. Curr. Appl. Phys. 2015, 15, 226-231. doi:10.1016/j.cap.2014.12.011

\section{License and Terms}

This is an Open Access article under the terms of the Creative Commons Attribution License (http://creativecommons.org/licenses/by/4.0), which permits unrestricted use, distribution, and reproduction in any medium, provided the original work is properly cited.

The license is subject to the Beilstein Journal of

Nanotechnology terms and conditions:

(https://www.beilstein-journals.org/bjnano)

The definitive version of this article is the electronic one which can be found at: doi:10.3762/bjnano.9.69 